\title{
LETRAMENTO CRÍTICO, REPRESENTATIVIDADE E ENSINO DE LÍNGUA INGLESA NO PIBID
}

\author{
Barbara Cabral Ferreira ${ }^{1}$ \\ Francieli Freudenberger Martiny ${ }^{2}$ \\ Laura Gabrielly dos Santos Bento ${ }^{3}$
}

Resumo: Este trabalho tem como objetivo relatar e refletir sobre uma aula de língua inglesa, cujo tema foi Representatividade da Mulher Negra na sociedade. A partir da leitura e discussão de textos sobre Letramento Crítico no ensino de língua inglesa no âmbito do Pibid, a aula mencionada foi planejada e ministrada em uma turma de oitavo ano do Ensino Fundamental, em uma escola municipal de João Pessoa - PB. No intuito de promover com os alunos um desenvolvimento da leitura crítica sobre sua própria realidade, a aula foi dividida em três momentos. No primeiro deles, a leitura de textos multimodais sobre um filme que aborda a temática pretendida. No segundo, a discussão sobre representatividade da mulher negra e outras minorias desprivilegiadas. No terceiro, a produção de cartazes e sinopses a respeito de um filme fictício, que também abordaria questões de representatividade. Essa sequência de atividades permitiu que os alunos refletissem sobre as diversas realidades com as quais convivem, uma vez que outras temáticas relevantes foram abordadas durante a aula. Desse modo, defendemos que a promoção do Letramento Crítico permite a percepção e a análise de temáticas relevantes aos alunos, o que pode ser instrumento que leve à atuação cidadã destes.

Palavras-chave: Letramento Crítico. Representatividade. Ensino de Língua Inglesa. Pibid.

\begin{abstract}
This paper aims to report and reflect on an English lesson whose theme was the representation of black women in society. Based on the reading and discussion of texts, in the scope of Pibid, about Critical Literacy in the teaching of English, the referred lesson was planned and taught to an 8th graders group, in a municipal school in João Pessoa - PB. In order to promote with the students the development of critical reading about their own reality, the lesson was divided into three moments. In the first one, the reading of multimodal texts

\footnotetext{
${ }^{1}$ Professora do Departamento de Letras Estrangeiras Modernas, Centro de Ciências Humanas, Letras e Artes, UFPB, Campus I - João Pessoa, Paraíba. Doutora em Linguística. Coordenadora do Pibid Letras Inglês. barbara.cabral.ferreira@gmail.com.

2 Professora do Departamento de Letras Estrangeiras Modernas, Centro de Ciências Humanas, Letras e Artes, UFPB, Campus I - João Pessoa, Paraíba. Doutora em Linguística. Coordenadora do Pibid Letras Inglês. francieli.freuden@gmail.com.

3 Aluna do Curso de Licenciatura em Letras Inglês, UFPB, Campus I - João Pessoa, Paraíba. Ex-bolsista, com apoio financeiro, do Pibid Letras Inglês - Edital Capes 07/2018. laurabentoufpb@gmail.com.
} 
about a movie that addresses the intended theme. In the second one, the discussion about the representation of black women and other underprivileged minorities. In the third one, the production of posters and blurbs about a fictional movie, which would also address issues of representativeness. This sequence of activities allowed students to reflect on the different realities where they live, once other relevant themes were addressed during the lesson. In this way, we argue that the promotion of Critical Literacy allows the perception and the analysis of topics that are relevant for students, which can be an instrument for their citizenship.

Key-words: Critical Literacy. Representation. English Language Teaching. Pibid.

\section{Introdução}

O Programa Institucional de Bolsa de Iniciação à Docência (doravante Pibid) constitui-se em uma ação da Política Nacional de Formação de Professores do Ministério da Educação (MEC). Gerenciado pela Coordenação de Aperfeiçoamento de Pessoal de Nível Superior (Capes), o Programa visa oportunizar aos discentes, ainda na primeira metade dos cursos de licenciatura, a aproximação e a vivência do cotidiano escolar de escolas de Educação Básica, iniciando os estudantes das licenciaturas em suas práticas docentes.

Na vigência do Edital Capes 07/2018, no âmbito da Universidade Federal da Paraíba (UFPB), havia vários subprojetos, dentre os quais o Subprojeto Letras Inglês, que se desenvolveu no período de agosto de 2018 a janeiro de 2020. Ele contava com a participação de duas coordenadoras, professoras de inglês do Departamento de Letras Estrangeiras Modernas (DLEM) da UFPB; uma supervisora, professora da escola-campo, e dez bolsistas, alunos do Curso de Letras Inglês.

Dentre as atividades desenvolvidas no âmbito do Subprojeto, os bolsistas participavam de reuniões semanais com as coordenadoras, para estudo, reflexão e planejamento das ações do grupo e das intervenções que seriam realizadas na escola e, ainda, frequentavam e participavam semanalmente das aulas da professora supervisora na escola, nas turmas do $5^{\circ}$ ao $9^{\circ}$ ano do Ensino Fundamental (EF). Em sua atuação na escola, os bolsistas foram divididos em duplas e cada uma dessas duplas se responsabilizava por planejar e aplicar as intervenções em uma única turma da escola, embora também acompanhasse e observasse aulas em outros grupos.

Vários temas foram estudados com os bolsistas nas reuniões semanais e o Letramento Crítico (LC) foi um deles, pois este se configurava como uma das principais propostas do Subprojeto. Desse modo, os bolsistas foram incentivados a ler e discutir textos tais como 
Jordão e Fogaça (2007); Janks (2010); Mattos e Valério (2010); Santos e Ifa (2013), dentre outros, que abordam o LC e o ensino de língua inglesa, além de buscarem essa integração em suas intervenções na escola-campo, consoante o que fora estudado durante as reuniões.

O presente texto apresenta um relato de cunho prático-reflexivo, fundamentado na descrição das atividades realizadas com um grupo de $8^{\circ}$ ano do EF e na análise de excertos dos diários reflexivos produzidos pela dupla de bolsistas que planejou e implementou tais atividades. Desse modo, o principal objetivo é apresentar e refletir sobre uma aula temática planejada por dois bolsistas e ministrada na turma do $8^{\circ}$ ano de uma escola municipal localizada em João Pessoa - Paraíba. Esta aula, conforme mencionado, tinha como objetivo não apenas ensinar inglês, mas desenvolver o LC junto aos alunos, ou seja, era intencionado redesenhar o entendimento dos textos em seu contexto social, percebendo as designações de papel definidas nos textos e proporcionando o despertar dos indivíduos como entendedores e agentes ativos em sua comunidade. Assim, através da descrição da aula e de recortes retirados dos diários reflexivos dos bolsistas, buscamos responder às seguintes perguntas: i. quais aspectos do LC foram abordados durante o planejamento e a ministração da aula sob análise? e ii. foi previsto, e alcançado, o trabalho com conteúdo linguístico-discursivo do inglês como possibilitador da construção do LC?

Para tanto, o presente texto se organiza da seguinte forma: na próxima seção são apresentadas algumas definições sobre Letramento Crítico, sua importância na formação de professores e sua relação com o ensino de Língua Inglesa. Depois disso, é descrito o contexto de atuação que possibilitou a geração dos dados aqui discutidos, bem como os critérios para a reflexão proposta. Em seguida, é proposta uma discussão a partir de trechos do planejamento e da efetivação da aula sob análise, bem como de excertos dos diários reflexivos dos bolsistas. A última seção oferece as considerações finais.

\section{Letramento crítico, formação de professores e ensino de língua inglesa}

A fim de melhor compreender como a aula relatada a seguir foi planejada e efetivada, primeiramente, é necessário entender o que vem a ser LC, a necessidade de que ele seja incluído na formação de professores e como ele pode ser integrado ao ensino de língua inglesa.

Mattos e Valério (2010) explicam que o LC toma como base os pressupostos da Teoria Crítica Social e da Pedagogia Crítica de Paulo Freire. Cervetti, Pardales e Damico (2001) 
ainda acrescentam a essas as Teorias Pós-estruturalistas. Segundo esses últimos autores, a partir do Pós-estruturalismo, o LC compreende os textos como construções ideológicas dentro de um sistema discursivo; da Teoria Crítica Social, compreende os textos como forças sociopolíticas e ideológicas, e da Teoria Freiriana vem a concepção de que as práticas de letramento devem sempre se preocupar com questões que envolvem a justiça, a liberdade e a igualdade. Desse modo, numa perspectiva de LC, nem o texto e nem a língua são compreendidos como elementos neutros. Mas sim, como o local em que posições ideológicas e sociopolíticas estão presentes, em que há luta, negociação e mudança.

O LC está comprometido com valores sociais tais como lutas pela igualdade, justiça e inclusão, entendendo a língua como recurso dinâmico e libertador, pois é por intermédio da língua que podemos transformar a nós mesmos e a sociedade, enquanto cidadãos conscientes. Sendo assim, a língua não é vista apenas como um instrumento de socialização, mas “[...] um instrumento de poder e de transformação social” (MATTOS; VALÉRIO, 2010, p. 139).

Quando falamos em LC e ensino, devemos entender que, nas disciplinas do currículo escolar, o LC não se configura enquanto método, nem técnica a ser empregada, mas como um meio para a construção da cidadania, uma perspectiva de ensino que busca capacitar o aluno a refletir criticamente sobre quem ele é na sociedade, de tomar posições e, por fim, de, se for do seu desejo, implementar ações que levem a transformar essa mesma sociedade, com vistas a promover a justiça social (MATTOS; VALÉRIO, 2010).

Porém, para que isso ocorra, é necessário que o professor também assuma uma postura crítica, que tenha consciência de seu papel enquanto mediador do saber, respeitando as experiências de mundo dos alunos para, a partir dessas experiências, levá-los à construção de novos conhecimentos, promovendo o desenvolvimento de uma consciência crítica (CAMARGO; SANTOS, 2016).

No que concerne ao papel do professor, é importante destacar que, conforme afirma Xavier (2016), com base em Hawkins (2011), a literatura que trata sobre formação de professores privilegia questões relacionadas à língua e a maneiras de ensinar, em detrimento das questões de cunho socioculturais, de letramento e de aprendizagem. E, como muitos professores nunca passaram por uma experiência de aprendizagem baseada em uma educação crítica, eles ainda têm dificuldade em incluir em suas aulas estratégias de ensino que não sejam as tradicionais (MAIA, 2015).

Pelas razões acima apresentadas, acreditamos ser importante que durante sua formação inicial, no Pibid, os bolsistas conheçam, estudem, discutam e busquem integrar o LC ao 
ensino do inglês, planejando e refletindo sobre suas práticas e desenvolvendo novas atitudes e perspectivas (DOURADO; MAIA, 2017). Desse modo, estamos contribuindo no desenvolvimento de professores para lidar com as novas demandas do mundo moderno e, consequentemente, para o ensino de língua inglesa voltado à formação de cidadãos críticos, dando "[...] oportunidades aos alunos de construir e negociar sentidos de forma coletiva, de rever suas crenças e de questionar as implicações de suas visões de mundo" (JORDÃO; FOGAÇA, 2007, p. 91).

Como podemos entender a partir do exposto, o LC busca o empoderamento do aprendiz, conduzindo-o a uma reflexão crítica sobre sua cultura e sobre o seu cotidiano e levando-o a questionar sua própria condição (FREIRE, 1970). Cervetti, Pardales e Damico (2001) afirmam que o LC leva à reflexão, transformação e ação, ou seja, o LC busca capacitar o aluno a, através da língua, atuar nas diferentes práticas sociais, posicionando-se e provocando mudanças, se for do seu desejo.

Diante do exposto, acreditamos que o LC pode ser integrado ao ensino de língua inglesa nas escolas de educação básica e, dessa maneira, o objetivo do ensino de inglês não se constitui apenas como o desenvolvimento das habilidades estritamente linguísticas do aluno na língua alvo, mas a formação de cidadãos críticos e conscientes.

Salientamos, ainda, que, de acordo com Mattos, Jucá e Jorge (2018), o LC foi introduzido no ensino de línguas estrangeiras no Brasil a partir de 2006, com as Orientações Curriculares Nacionais para o Ensino Médio (OCEM). Mais recentemente, verificamos que a Base Nacional Comum Curricular (BNCC), documento normativo que atualmente rege as aprendizagens essenciais que devem ser desenvolvidas na Educação Básica brasileira, traz em seu texto conceitos como o de cidadania e criticidade no ensino de língua inglesa, orientando que

[...] o estudo da língua inglesa pode possibilitar a todos o acesso aos saberes linguísticos necessários para engajamento e participação, contribuindo para o agenciamento crítico dos estudantes e para o exercício da cidadania ativa, além de ampliar as possibilidades de interação e mobilidade, abrindo novos percursos de construção de conhecimentos e de continuidade nos estudos. É esse caráter formativo que inscreve a aprendizagem de inglês em uma perspectiva de educação linguística, consciente e crítica, na qual as dimensões pedagógicas e políticas estão intrinsecamente ligadas (BRASIL, 2017, p. 241).

Sendo assim, em conformidade com o disposto na BNCC, a sala de aula de inglês pode se tornar um espaço em que os alunos se sintam confortáveis para falar, discutir, negociar, compartilhar suas experiências, vivências e visões de mundo, negociar, construir e 
reconstruir sentidos e ampliar suas perspectivas, percebendo-se enquanto sujeitos críticos e, ainda, compreender que as línguas são usadas de formas diferentes, em contextos diferentes, com pessoas diferentes e com propósitos diversos, como afirmam Jordão e Fogaça (2007).

Essas discussões, inclusive, poderão ser realizadas na própria língua materna do aluno, tendo em vista que é necessário que o aluno seja capaz de expressar o que pensa plenamente e que o não-domínio da língua estrangeira poderia gerar constrangimento ou silenciamento de alguns alunos. No entanto, em se tratando de uma aula de língua inglesa, também será necessário que sejam realizadas atividades que oportunizem o exercício de práticas linguístico-discursivas na língua estrangeira (JORDÃO; FOGAÇA, 2007; SANTOS; IFA, 2013), como veremos na aula do $8^{\circ}$ ano na escola-campo do Pibid Letras Inglês da UFPB.

\section{O projeto Representatividade da Mulher Negra: aspectos metodológicos}

Como mencionado acima, uma das propostas do Subprojeto Letras Inglês na UFPB era desenvolver estratégias de ensino que possibilitassem a aprendizagem da língua inglesa a partir do trabalho com LC. Desse modo, juntamente com a leitura, o estudo e a discussão de textos sobre o tema, os bolsistas eram incentivados a planejar e ministrar aulas para as turmas que acompanhavam na escola-campo.

Durante toda a vigência do projeto, os bolsistas frequentaram, observaram e participaram das aulas da supervisora na escola-campo, realizando pequenas intervenções durante essas aulas. Porém, diante do interesse e do envolvimento evidenciado, foi decidido que na última semana de cada mês os bolsistas, organizados em duplas, seriam responsáveis pelas aulas completas nas turmas, sempre acompanhados pela supervisora. Para isso, eles precisavam planejar essas aulas com as coordenadoras e demais participantes do projeto.

Nas reuniões semanais, havia espaço para que os bolsistas, além de realizarem planejamentos de forma coletiva, pudessem relatar o que haviam observado na escola durante a semana. O projeto Representatividade surgiu a partir da discussão sobre tais observações, tendo como meta levar para as turmas acompanhadas pelos bolsistas temas interessantes e próximos da realidade dos alunos e, ao mesmo tempo, promover seu contato com os conteúdos linguístico-discursivos que a supervisora trabalhava em cada turma. Dentre algumas das inquietações levadas pelos bolsistas para as reuniões do projeto estavam questões de autoestima, tais como alunas que se achavam feias porque tinham cabelos crespos; de inclusão, tais como alunos com deficiência que sofriam bullying ou eram evitados pelos 
colegas de turma; e de preconceitos, tais como xingamentos que alguns alunos recebiam por causa da cor de sua pele, sua forma física ou orientação sexual.

Sendo assim, os bolsistas decidiram que era importante tratar sobre a temática da representatividade e da aceitação com as turmas da escola e selecionaram temas a serem trabalhados em cada turma, relacionados a minorias sociais. O propósito dessas intervenções era construir com os alunos um conhecimento acerca das injustiças sociais por eles vivenciadas e de como elas poderiam ser vistas, enfrentadas e modificadas.

Nas turmas do $5^{\circ}, 6^{\circ}$ e $7^{\circ}$ ano foi escolhido o tema Representatividade da Pessoa com Deficiência $^{4}$, já que a escola tinha mais de 30 alunos com deficiências variadas matriculados nessas turmas. Já no $8^{\circ}$ ano, o tema escolhido foi Representatividade da Mulher Negra, pois havia um grande número de alunas negras na turma. No $9^{\circ}$ ano, a temática selecionada foi Representatividade da Mulher sob uma perspectiva histórica. A aula apresentada e discutida no presente texto remete à aula introdutória do projeto, elaborada e ministrada para o grupo do $8^{\circ}$ ano.

Além das reuniões, das observações e das intervenções nas turmas, durante a vigência do Subprojeto, os bolsistas também escreviam diários reflexivos. Segundo Dias (2011), pesquisas sobre trabalho docente no âmbito da Linguística Aplicada destacam o uso do diário reflexivo como uma das práticas de letramento que favorecem o desenvolvimento de uma postura crítico-reflexiva. Medrado (2012), por sua vez, afirma que, ao textualizar suas experiências, o professor em formação, não apenas as registra no papel, mas também as organiza e lhes atribui significado. Desse modo, a autora destaca que esse tipo de relato contribui para a compreensão das experiências de ensino e do processo de tornar-se professor.

A partir dessa compreensão, os diários escritos pelos bolsistas foram utilizados no Subprojeto não apenas com o intuito de registrar as atividades desenvolvidas, mas também com o objetivo de proporcionar a reflexão sobre a prática e a formação docente. Nos diários reflexivos, os bolsistas escreviam acerca de suas percepções sobre o projeto, sobre sua própria formação, sobre suas emoções e sentimentos e sobre as atividades desenvolvidas na escola e fora dela, tais como eventos, reuniões e oficinas (ANDRADE et al, 2018; CORREA et al, 2019). Esses diários eram compartilhados por todos os participantes em uma nuvem de dados e as coordenadoras sempre liam e utilizavam o que os bolsistas traziam em seus relatos para organizar, avaliar e (re)pensar as ações que estavam sendo desenvolvidas. Os diários dos

\footnotetext{
${ }^{4}$ Optamos pela utilização do termo Pessoa com Deficiência (PCD) em consonância com as convenções adotadas nos estudos da área (cf. MEDRADO, 2012; MEDRADO; DANTAS, 2014).
} 
bolsistas que atuaram no $8^{\circ}$ ano, então, são documentos que podem contribuir para reflexão sobre a aula ministrada nessa turma.

O grupo em que a aula relatada foi ministrada $-8^{\circ}$ ano - era formado por 45 alunos, numa faixa etária entre 12 e 14 anos. As aulas de inglês da turma ocorriam nos dois primeiros horários das segundas-feiras, totalizando 80 minutos. A aula introdutória sobre a Representatividade da Mulher Negra apresentada e discutida neste trabalho ocorreu no dia 22 de abril de 2019. Para ela, a dupla de bolsistas que acompanhava o grupo, identificados neste texto como Bolsista A e Bolsista B, escolheu abordar a realidade das mulheres negras estadunidenses, na década de 1960 e sua participação apagada na história mundial.

Foi utilizado um filme na tentativa de expor os males que a segregação trouxe não só à mulher negra, mas a toda a população negra do país. Morrison (2019) desvela o racismo americano ao pontuar que a esquemática do "tornar-se [norte]americano" se define em abandonar as características do país do imigrante e desvincular-se de sua cultura natal, algo que não foi permitido aos africanos e seus descendentes, levando-os a uma cadeia de racismo explícito, consumado no ódio pela cor da pele negra.

Tendo essa compreensão como fundamento subjacente ao trabalho dessa dupla de bolsistas, a aula foi planejada no sentido de que, ao perceber a cultura do outro, os participantes pudessem compreender sua própria cultura e seu papel nela. Isso porque proporcionar um espaço para o entendimento das realidades alternativas àquelas em que os alunos se encontravam tornava-se essencial para que eles pudessem se perceber enquanto agentes, cidadãos ativos em seu meio social, fomentando uma "[...] participação em termos críticos, somente como poderia ser possível a sua transformação em povo, capaz de optar e decidir" (FREIRE, 1967, p. 110). O princípio que embasou a proposição da aula sustentava que a apresentação aos alunos de diferentes realidades, principalmente as mais desprivilegiadas e minorizadas, poderia abrir possibilidades de questionamento, proporcionando uma tomada de ação baseada em sua criticidade, enraizada na cidadania.

Tendo descrito brevemente a atuação do Subprojeto Pibid Letras Inglês da UFPB, o presente texto propõe um relato de cunho prático-reflexivo sobre as ações e reflexões a respeito do ensino de língua inglesa a partir da noção de LC. Desse modo, ele não apenas apresenta o relato da experiência vivida, como também dá acesso a uma dupla interpretação das ações implementadas. A primeira interpretação remete àquela realizada pelos próprios bolsistas em seus diários reflexivos, dos quais foram selecionados alguns excertos para ilustrar como aconteceu seu contato com a noção de LC e a temática proposta para o grupo de 
$8^{\circ}$ ano. A segunda interpretação é possível a partir da análise posterior tanto das atividades implementadas com esse grupo, como dos próprios excertos dos diários reflexivos.

Destarte, este texto busca realizar um estudo de base exploratória (GIL, 2008) a partir de documentos (LAKATOS; MARCONI, 2003) produzidos pelos Bolsista A e Bolsista B durante a vigência do projeto. Para tanto, inicialmente é realizado um relato a respeito das atividades planejadas, seguido de excertos dos diários reflexivos produzidos pelos bolsistas. Em seguida, é proposta uma reflexão embasada nos pressupostos do LC e dos objetivos almejados pelo projeto Representatividade da Mulher Negra.

\section{A aula planejada e ministrada}

O tema escolhido para essa aula temática, como já mencionado, foi Representatividade da Mulher Negra e foram utilizadas, como ponto de partida, as vivências de mulheres negras na época da segregação estadunidense. Para seu desenvolvimento, foram empregados cenas e pôsteres do filme Estrelas Além do Tempo ${ }^{5}$ (2017) e, através desses diferentes gêneros textuais, buscou-se debater e trazer ao conhecimento dos alunos alguns exemplos de vivências de mulheres negras estadunidenses daquele período - década de 1960, relacionando-as à realidade dos alunos.

A aula começou com uma pequena atividade introdutória intitulada "Era uma vez..." para atrair a atenção dos alunos. Nessa pequena história de faz de conta, os bolsistas falaram aos alunos sobre eles mesmos e em como eles estavam empolgados e felizes para realizar aquela aula tão esperada e que precisariam da colaboração e participação dos alunos para que tudo ocorresse melhor do que esperado.

Para dar início ao tema, o pôster do filme Estrelas Além do Tempo foi apresentado e os bolsistas perguntaram aos alunos, em língua materna, o que eles percebiam naquelas imagens. A intenção foi incentivar a leitura daquele texto multimodal e verificar o que os alunos perceberiam com essa leitura rápida inicial para, a partir dela, introduzir a temática da aula.

Figura 1: Pôster do filme utilizado em aula

\footnotetext{
${ }^{5}$ Em inglês, Hidden Figures.
} 


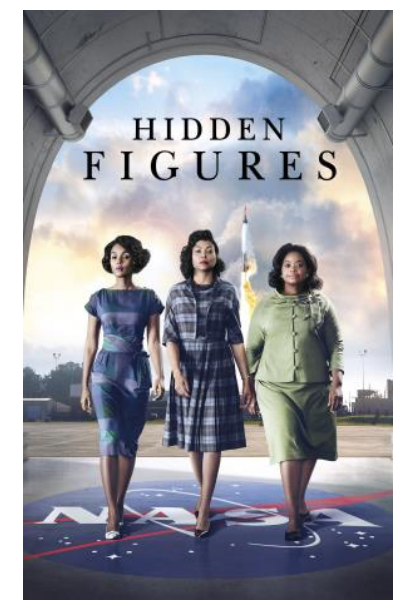

Disponível em: https://family.20thcenturystudios.com/movies/hidden-figures. Acesso em: 07 de janeiro de 2020

Ao passar a palavra para os alunos, eles se entusiasmaram com o fato de serem protagonistas e comentaram sobre vários aspectos da imagem como, por exemplo, o foguete no plano de fundo, o nome da NASA sob os pés das atrizes, o ambiente em que elas estavam, suas vestes de época e, à medida que mais leituras eram elaboradas por eles, os bolsistas escreviam no quadro, em inglês, o que eles comentavam, construindo, assim, um quadro com o vocabulário relativo àquela leitura inicial. Dois alunos mencionaram o fato das protagonistas do filme serem mulheres negras e era exatamente neste ponto que os bolsistas pretendiam chegar.

Embora na turma houvesse um grande número de alunos negros, percebeu-se que eles assistiam esse início da aula em silêncio, até que uma aluna passou a falar e fazer questionamentos e observações sobre o tema da aula, relacionando ao preconceito que ela sofria por ser negra. Então, chegando ao tema central da aula, os bolsistas perguntaram aos alunos porque a mulher negra é desprivilegiada e silenciada na sociedade.

Os estudantes, por sua vez, silenciaram, talvez por não encontrarem uma resposta fácil e rápida para aquela pergunta naquele momento. Então, os bolsistas começaram a construir as respostas com eles, através de perguntas e apresentação de trechos do filme. Os bolsistas e os alunos conversaram sobre a escravização e em como isso influencia, até os dias atuais, a vida da mulher negra (e dos negros, em geral) e a maneira como o racismo a priva de ter sua contribuição na história da humanidade contada. Para isto, foi utilizado o trailer do filme e uma cena específica em que uma das protagonistas vai à corte para conseguir o direito de frequentar uma faculdade de engenharia, que era apenas para brancos.

Figura 2: Grupo do $8^{\circ}$ ano assistindo aos vídeos 


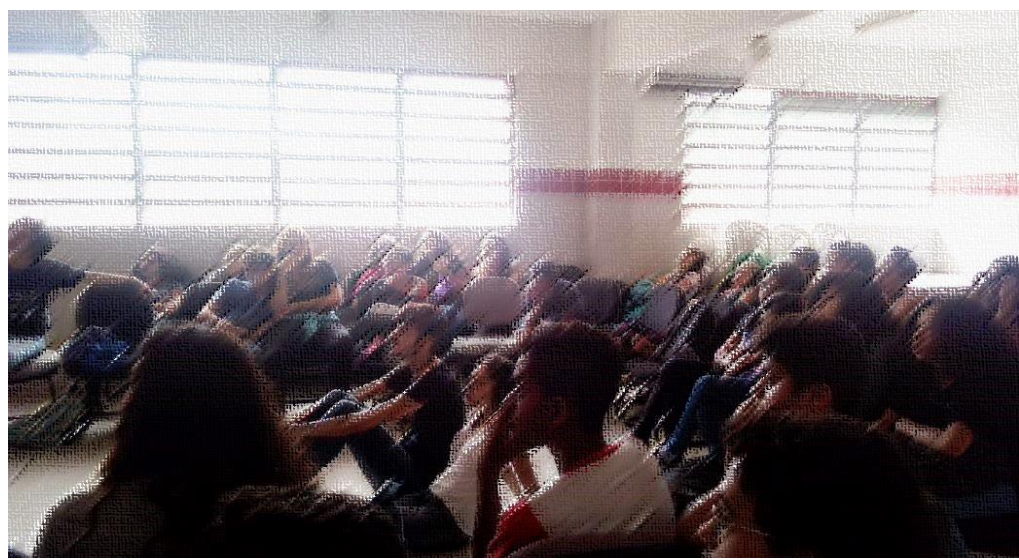

Fonte: Arquivo do Subprojeto Letras Inglês

Ao levar para os alunos o conhecimento, através da sinopse da história, de que aquele filme fora baseado em fatos reais, perceberam-se os suspiros de revolta e angústia de alguns e a falta de compreensão de outros, acerca de como aquela realidade afetou e afeta drasticamente a vida de tantas pessoas.

Dando continuidade à aula, após a parte inicial, promovendo a discussão e a leitura dos textos, os bolsistas explicaram aos alunos que eles deveriam elaborar, em grupos, um pôster e uma sinopse de um filme que possuísse como tema a Representatividade da Mulher Negra ou de algum outro grupo social desprivilegiado historicamente. O objetivo de tal atividade era de que os alunos pudessem produzir textos em inglês, a partir dos textos que eles viram e que, ao discutirem com os colegas nos grupos e conhecerem a realidade de outras pessoas, pudessem compreender a importância do respeito a tais vivências.

Figura 3: Grupo elaborando seu pôster sob supervisão dos bolsistas

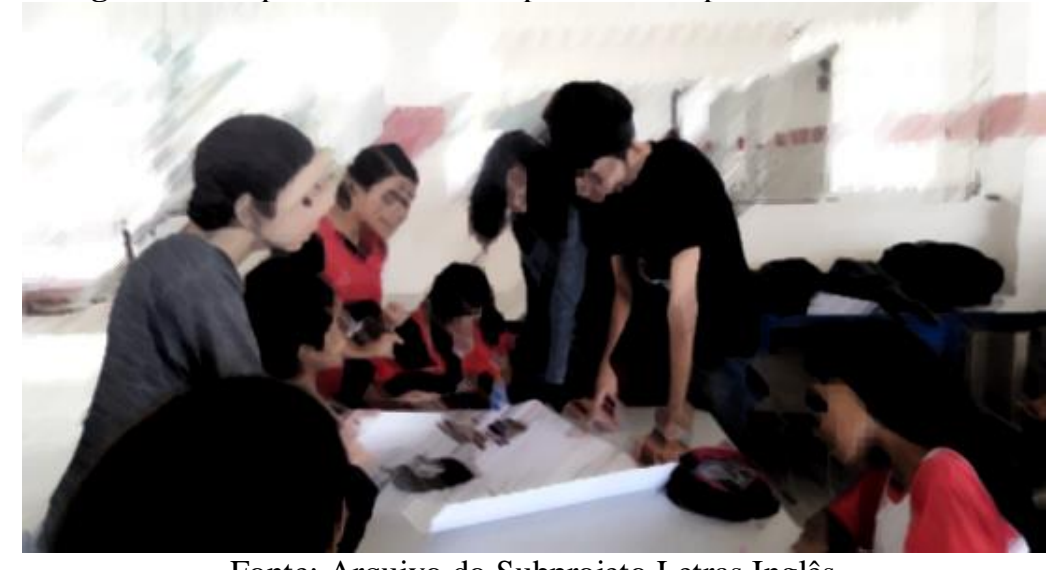

Fonte: Arquivo do Subprojeto Letras Inglês

Durante a discussão nos grupos e elaboração dos pôsteres, os bolsistas acompanhavam o trabalho em cada grupo, oferecendo orientações e tirando dúvidas. 


\section{Refletindo sobre a experiência}

A partir da aula descrita, em que se buscou integrar o LC ao ensino de inglês, foi possível observar algumas questões acerca do planejamento e da condução da aula e sobre o impacto que a experiência gerou, tanto nos alunos da escola-campo, como na formação docente dos bolsistas envolvidos.

No que diz respeito ao planejamento e condução da aula, pode-se perceber que, em alguns momentos em que o tema foi discutido, foi necessário o uso da língua materna, o que já era esperado pelos bolsistas. Como vimos anteriormente, tanto a língua materna quanto a estrangeira podem ser utilizadas em sala de aula, em momentos diversos, com vistas à construção do saber.

No entanto, percebe-se que além das discussões em língua materna, a língua inglesa foi trabalhada durante a leitura, na construção do vocabulário no quadro, correspondente às ideias que os alunos falavam sobre o pôster, bem como através dos trechos do filme que foram reproduzidos, levando os alunos a perceberem a sonoridade e a pronúncia das palavras que os atores falavam em inglês. Além disso, em suas produções, o título do filme que os alunos criaram e as palavras-chave da sinopse foram escritos em língua inglesa, com o auxílio do vocabulário que foi construído no início da aula, no quadro (ex: racismo, sexismo, empoderamento, guerreiras, trabalho pesado ${ }^{6}$ ). Sendo assim, a aula proporcionou aos alunos o exercício de práticas linguístico-discursivas, tanto em língua materna, quanto em inglês, como percebemos através do Excerto 1, retirado do diário reflexivo do bolsista A:

\section{Excerto 1:}

Para desenvolver o inglês e por suas mentes criativas para trabalhar, dividimos a sala em três grandes grupos, e cada grupo deveria fazer um poster e uma sinopse sobre um filme que falasse sobre representatividade, que o ideal seria sobre a mulher negra, mas tudo bem se fosse sobre outra parte desprivilegiada da sociedade. O inglês não podia ficar de fora, mas como conhecemos a realidade deles, pedimos para que utilizassem palavras-chave, como as que construímos no quadro (ex: Racism, Sexism, Empowerment, Warriors, Hard Work), em inglês e o resto do texto podia ser em português.

Contudo, ao lançar novamente um olhar para a aula, observa-se que alguns aspectos poderiam ser modificados e, ainda, que alguns desafios foram encontrados. A questão do tempo, por exemplo, foi um grande desafio, pois a duração da aula era curta. Embora a aula tivesse um total de 80 minutos de encontro, por ser a primeira aula do dia, era comum a chegada dos alunos em sala com atraso, além da necessidade de organização do material

\footnotetext{
${ }^{6}$ Em inglês, Racism, Sexism, Empowerment, Warriors, Hard Work.
} 
individual e do espaço, e da realização da chamada no início do encontro. Além disso, ao final, era necessário que os alunos tivessem alguns minutos para se organizarem para a locomoção até a outra sala na troca de disciplinas. No dia da aula, ainda houve um agravante, pois alguns alunos começaram a brigar na porta da sala, como relatado pelo Bolsista B em seu diário reflexivo:

\section{Excerto 2:}

No primeiro bom dia já rolou um barulho na porta, dois alunos tavam se atracando lá fora, uma menina e Z. Nos socos, ela saiu sangrando coitada. Corri pra lá e a Bolsista A segurou os meninos na sala. Eles foram levados pra diretoria, mas logo voltaram. Os meninos na bagunça deles, e aí comecei contando uma historinha pra eles. "Era uma vez..." E aí, todos calados. Engraçado, eles são maiores, mas essa estrutura ainda prende eles.

O Bolsista B, então, para poder acalmar a turma e dar início à aula improvisou uma introdução, como descrevemos anteriormente, contando uma história de "Era uma vez...", sobre a presença deles ali e sobre aquela aula que iriam ministrar. Ainda, como a turma era composta de mais de 40 alunos, outro desafio foi motivá-los a participar e conduzir a aula de maneira que envolvesse todos os alunos para que eles não se desinteressassem e começassem a se envolver em conversas e atividades paralelas. Porém, de acordo com o relatado pelo Bolsista B, os alunos participaram da discussão e isso foi bastante marcante para os bolsistas:

\section{Excerto 3:}

S., uma aluna negra, começou a participar muito e ela sempre foi muito calada. Esse momento foi bem impactante pra nós, a participação daquela aluna pareceu fazer com que o real sentido da aula começasse a surgir. Falamos sobre segregação, história dos Estados Unidos, um monte de coisa. Rendeu, os alunos começaram a questionar sobre os motivos daquilo tudo, e eles não conseguiam segurar a sua indignação ao descobrir que tudo aquilo era uma questão de preconceito.

No entanto, devido ao curto tempo do encontro, a discussão da temática teve que ser encerrada, para que houvesse tempo para as demais atividades planejadas. Mesmo assim, não foi possível que os alunos terminassem os pôsteres que estavam criando e a supervisora concordou que o encontro seguinte fosse para dar continuidade àquela atividade e ao tema trabalhado, conforme relato do Bolsista B:

\section{Excerto 4:}

Os meninos agora iam colocar em prática o que eles conseguiram entender sobre "Representatividade" usando cartolinas e fazendo seus próprios pôsteres de filme com sua criatividade em ação, e do lado da sua sinopse colocar emojis simbolizando a emoção que sentiram naquela aula. Tudo foi encaminhado, eles colaram recortes de revistas que tinham na escola, e ficaram de terminar na outra semana porque não deu tempo. No final ainda rolou um parabéns pra mim, foi ótimo. 
A partir da experiência, os bolsistas perceberam que, no planejamento, é necessário pensar na questão do tempo e do número de atividades que podem ser realizadas em um encontro, uma vez que uma sequência de atividades melhor organizada e distribuída permite um aprofundamento maior na temática tratada e maior calma no desenvolvimento das tarefas propostas.

Após a aula, também percebeu-se que, caso houvesse uma sequência de dois encontros, seria possível, ainda, incorporar no planejamento a apresentação de falas de mulheres negras sobre suas vivências na época em questão (1960 - momento em que a segregação estadunidense se encontrava em vigor) e, com intuito comparativo, depoimentos de mulheres negras e suas vivências nos dias atuais, especialmente de narradoras e protagonistas brasileiras.

A aula também levou os bolsistas a entenderem que, em atividades que envolvam LC, é necessário dar voz aos alunos e escutá-los, conduzindo a aula a partir do que eles possam trazer, o que também pode consumir bastante tempo da aula, principalmente se os alunos se interessarem e se identificarem com o tema proposto.

Como a temática escolhida pelos bolsistas foi bem aceita e bastante discutida pela turma, observou-se que, realmente, é necessário que o professor tenha um olhar atento, observando e conhecendo a realidade e necessidades das turmas. Dessa forma, os bolsistas sempre conversavam com os alunos e observavam seu comportamento para identificar temas relevantes e interessantes para as turmas nas suas próximas aulas.

Com relação à produção final proposta aos alunos, observou-se que eles escolheram temáticas atuais para seus filmes sobre representatividade e os títulos que escolheram foram: Sem-teto, O poder de uma mulher e Sempre juntos ${ }^{7}$. Cada um desses trabalhos trouxe temas relevantes e presentes no contexto dos alunos e foram representados de maneira contundente e interessante. Durante a aula, os alunos tiveram a oportunidade de trocar ideias e compartilhar vivências com os colegas de classe e, desse modo, puderam conhecer melhor a realidade do outro, se aproximar e (re)pensar sobre questões que envolvem representatividade e desigualdades sociais.

O primeiro grupo, com o filme Homeless, escolheu fazer um filme no formato documentário, que seria sobre a vida da população desabrigada das grandes cidades do Brasil. O segundo grupo, A woman's power, decidiu abordar as experiências de uma mulher negra e

\footnotetext{
${ }^{7}$ Em inglês, Homeless, A woman's power e Always together.
} 
todas as situações preconceituosas que ela enfrentava em seu cotidiano. Por fim, o terceiro grupo, Always together, trouxe o tema de diferenças entre classes sociais e os desprivilégios de uma família pobre em comparação a uma família rica. Os estudantes utilizaram materiais disponibilizados pelo Pibid e pela escola-campo (cartolina, revistas, jornais e até desenhos produzidos por eles mesmos).

Figura 4: Pôsteres produzidos pelos alunos

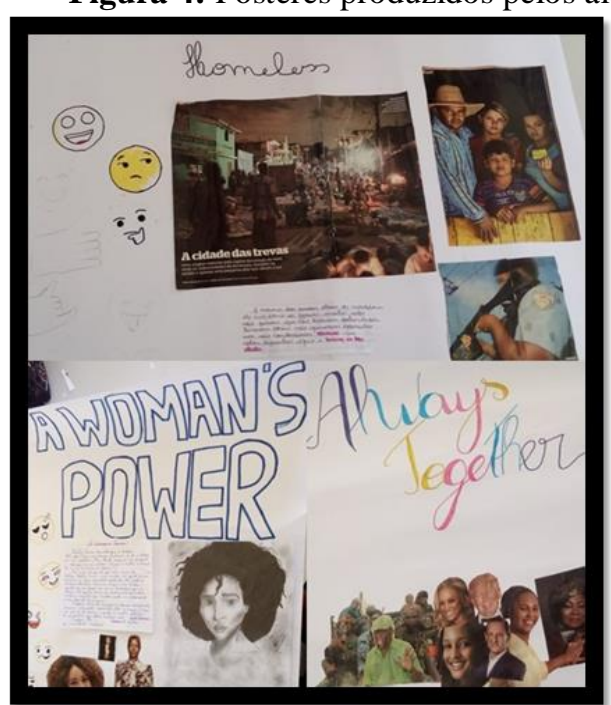

Fonte: Arquivo do Subprojeto Letras Inglês

Com o intuito de avaliar o quanto os alunos se envolveram e gostaram das atividades realizadas na aula e na construção de seus textos, eles foram orientados pelos bolsistas a utilizar emojis para representar as emoções que sentiram naquela aula (ver Figura 4). Pôde-se perceber que os emojis utilizados pelos alunos se encontravam num leque de felicidade, empolgação, reflexão, estudos e paixão. Alguns ainda se sentiram um pouco desinteressados e utilizaram emojis para retratar isto também, mas a maioria dos alunos se engajou e os bolsistas obtiveram um retorno muito positivo, com comentários de alunos relatando como aquela aula temática tinha influenciado em sua formação. Dessa maneira, percebeu-se que essa aula, embasada no LC, teve um impacto positivo, tanto para os alunos, quanto para os bolsistas do Pibid, conforme narrado no relato reflexivo do Bolsista $\mathrm{A}$. 


\section{Excerto 5:}

E apesar de ter sido um dia bem cansativo, foi incrível conversar com eles sobre todas essas coisas tão importantes. Letramento crítico, pode ficar, querido, aceita um café?

Por fim, verificou-se, com a aula, que é possível integrar o LC ao ensino de língua inglesa e que essa experiência levou os bolsistas a enxergarem o ensino de inglês de uma maneira diferente da tradicional, influenciando na formação docente dos mesmos e levandoos a compreender a importância de se observar a turma e o contexto em que os alunos estão inseridos, além de levar temas e conteúdos que se aproximam de suas realidades e lhes levam a refletir e se posicionar criticamente, como seres sociais e conscientes da importância de sua participação na sociedade e no meio em que vivem, respeitando a si mesmos e aos demais, suas vivências, ideias, opiniões e experiências.

\section{Considerações finais}

As considerações a respeito do planejamento e da realização da aula aqui relatada e analisada devem ser conduzidas a partir de algumas questões contextuais. A primeira delas diz respeito ao fato de os bolsistas atuantes no projeto estarem cursando a primeira metade do Curso de Letras Inglês, não possuindo experiência anterior no ensino. Além disso, dadas as características do Pibid estabelecidas pelo Edital Capes 07/2018, tais bolsistas não estavam habituados a conduzirem uma aula completa. A oportunidade para que essa aula se efetivasse surgiu do envolvimento dos bolsistas com os alunos da escola-campo, proporcionado pela constante observação e participação nas aulas ministradas pela professora supervisora.

Desse modo, se a integração do LC no ensino de inglês em escolas regulares pode se caracterizar como um grande desafio para professores mais experientes, para esses bolsistas, essa demanda constitui-se ponto de partida para sua prática docente. Sendo assim, a possibilidade de construir a aula discutida neste texto proporcionou aos integrantes do projeto uma nova perspectiva com relação ao ensino de inglês.

Refletindo, assim, a respeito da primeira questão norteadora, que indaga sobre os aspectos do LC abordados nesta aula, é possível perceber que a temática selecionada surgiu da relação estabelecida entre os bolsistas e os alunos da escola-campo. Os temas abordados, que podem ser considerados tabus em alguns contextos, eram de fato significativos para esse 
contexto de atuação. Além disso, foi explicitamente objetivada a discussão sobre igualdade, justiça e inclusão, outro aspecto relevante para o trabalho com o LC.

Outro ponto significativo da atuação dos bolsistas na aula aqui discutida diz respeito à consideração de seus alunos como participantes e protagonistas das atividades promovidas. Durante a condução da aula, os alunos foram convidados a compartilhar e discutir criticamente sobre suas próprias vivências e realidades, em um ambiente que se propunha seguro e receptivo. Objetivava-se, assim, que o reconhecimento de outras realidades, distantes geográfica ou temporalmente, levasse ao questionamento de sua própria condição.

Também, o papel do professor no desenvolvimento do LC é um aspecto significativo. Os bolsistas, ao respeitarem as experiências vividas pelos alunos, seja na definição da temática ou na condução das atividades, agiram como mediadores do conhecimento. Essa postura, ainda que seja amplamente advogada nos cursos de formação de professores, pode ser bastante desafiadora, seja para os docentes ou para os próprios alunos da escola básica. Embora não seja possível averiguar se houve construção de novos conhecimentos, questionamento de crenças ou ampliação de perspectivas, pode-se argumentar que o caminho para esses processos de desenvolvimento foi estabelecido.

No que tange à segunda pergunta norteadora, que busca perceber a integração do trabalho com aspectos linguístico-discursivos do inglês à promoção do LC, é possível identificar a preocupação dos bolsistas com essa demanda. Em seus relatos reflexivos, os dois bolsistas explicitam quais aspectos da língua foram enfatizados durante a aula e como as tarefas propostas promoveram conhecimento de inglês junto aos alunos. Entretanto, não foi possível observar o uso dessa língua enquanto instrumento de transformação ou mesmo de mediação ou negociação de sentidos. Essa limitação pode ser atribuída à própria proficiência dos alunos na escola-campo ou ao fato de que a intervenção tenha ocorrido pontualmente e, de certa forma, de maneira acelerada, para que ficasse restrita a apenas os dois horários do dia combinado.

Desse modo, ao pontuar não somente os procedimentos seguidos no planejamento e na condução de uma aula de inglês na escola regular, como também as limitações e sugestões de modificação dessa prática, foi intencionado compartilhar as experiências de formação docente e de ensino de inglês. É primordial que tal partilha de situações práticas, aliadas às ponderações supostamente teóricas que as sustentam, seja efetivada de maneira recorrente em contexto acadêmico, para que haja o fortalecimento do coletivo de professores, constantemente envolvidos em seu próprio desenvolvimento e formação. 


\section{Referências}

ANDRADE, Débora, et al. Caleidoscópio de emoções: sentimentos à flor da pele. Pôster. XX Encontro de Iniciação à Docência. UFPB, João Pessoa, 2018.

BRASIL, Ministério da Educação. Base Nacional Comum Curricular. Versão Final. Brasília: Ministério da Educação, 2017. Disponível em: http://basenacionalcomum.mec.gov.br/images/BNCC_EI_EF_110518_versaofinal_site.pdf. Acesso em: 09 de novembro de 2020.

CAMARGO, Jonathan de Paula; SANTOS, Delvânia Aparecida Góes dos. Letramento crítico: um experimento de ensino da língua inglesa na feira da Vila Aurora, Mato Grosso, Brasil. Revista Educação, Cultura. Sociedade, Sinop, v. 6, n. 1, p. 275-286, jan./jun. 2016. Disponível http://sinop.unemat.br/projetos/revista/index.php/educacao/search/authors/view?firstName=D elv\%C3\%A2nia\&middleName $=$ Aparecida $\% 20 \mathrm{G} \% \mathrm{C} 3 \% \mathrm{~B} 3 \mathrm{es} \% 20 \mathrm{dos} \&$ lastName $=$ Santos\&affi liation $=\&$ country $=$. Acesso em 05 de agosto de 2019.

CERVETTI, Gina; PARDALES, Michael J.; DAMICO, James S. A Tale of Differences: Comparing the Traditions, Perspectives, and Educational Goals of Critical Reading and Critical Literacy, 2001. Disponível em: https://www.semanticscholar.org/paper/A-TALE-OFDIFFERENCES\%3A-COMPARING-THE-TRADITIONS\%2C-OF-Cervetti-

Pardales/c3d43e79a71767b6f5dc848f406a46006de9e180. Acesso em: 05 de janeiro de 2021.

CORREA, Helba. Estratégias de inclusão em aulas de inglês: atividades adaptadas no ensino de crianças com deficiência. Pôster. XXI Encontro de Iniciação à Docência. UFPB, João Pessoa, 2019.

DIAS, Sandra Maria Araújo. Revelações sobre o agir docente em um diário reflexivo. In: MEDRADO, Betânia Passos; PÉREZ, Mariana (orgs.). Leituras do Agir Docente: A atividade educacional à luz da perspectiva interacionista sociodiscursiva. Campinas: Pontes, 2011.

DOURADO, Maura; MAIA, Angélica. Ações inovadoras no Ensino Regular da Paraíba: em cena o subprojeto letras-inglês. In: LIMA, R.; SILVA, M. (orgs.). Formação de professores: contribuições do PIBID/UFPB. João Pessoa: Editora UFPB, 2017, p. 205-220.

EDMUNDO, Eliana Santiago Gonçalves. Letramento crítico no ensino de inglês na escola pública: planos e práticas nas tramas de pesquisa. Campinas: Pontes, 2013.

FREIRE, Paulo. Educação como prática de liberdade. Rio de Janeiro: Paz e Terra, 1967.

Pedagogia do Oprimido. Rio de Janeiro: Edições Paz e Terra, 1970.

GIL, Antonio Carlos. Como elaborar projetos de pesquisa. 4. ed. São Paulo: Atlas, 2008. 
JANKS, Hilary. Literacy and Power. London and New York: Routledge. 2010.

JORDÃO, Clarissa; FOGAÇA, Francisco Carlos. Ensino de inglês, letramento crítico e cidadania: um triângulo amoroso bem-sucedido. Línguas e Letras: Estudos Linguísticos, v. 8 , n. 14, p. 79-105. jan/jul 2007. Disponível em: http://erevista.unioeste.br/index.php/linguaseletras/article/view/906/770. Acesso em: 05 de agosto de 2019.

LAKATOS, Eva Maria; MARCONI, Marina de Andrade. Fundamentos de metodologia científica. 5. ed. São Paulo: Atlas, 2003.

MAIA, Angélica. Subprojeto Letras-Inglês (PIBID-UFPB): uma proposta de letramento crítico na língua inglesa. Ao Pé da Letra. Recife, v. 17.1, p. 9-28, 2015. Disponível em: https://periodicos.ufpe.br/revistas/pedaletra/article/view/231853/26035. Acesso em: 18 de agosto de 2020.

MATTOS, Andréa Machado de Almeida; VALÉRIO, Kátia Modesto. Letramento crítico e ensino comunicativo: lacunas e interseções. Revista Brasileira de Linguística Aplicada. Belo Horizonte, v. 10, n. 1, p. 135-158, 2010. Disponível em: https://www.scielo.br/pdf/rbla/v10n1/08.pdf. Acesso em: 05 de agosto de 2019.

MATTOS, Andrea Machado de Almeida; JUCÁ, Leina; JORGE, Míriam Lúcia dos Santos. Formação crítica de professores: por um ensino de línguas socialmente responsável. Pensares em Revista, n. 15, maio 2019. ISSN 2317-2215. Disponível em: <https://www.epublicacoes.uerj.br/index.php/pensaresemrevista/article/view/38666>. Acesso em: 09 jan. 2021. doi: https://doi.org/10.12957/pr.2019.38666. Acesso em: 05 de janeiro de 2021.

MEDRADO, Betânia Passos. Tornando-se professor: a compreensão de graduandos em Letras sobres a atividade educacional. In: MEDRADO, Betânia Passos; REICHMANN, Carla Lynn. Projetos e práticas na formação de professores de língua inglesa. João Pessoa: Editora da UFPB, 2012.

MEDRADO, Betânia Passos; DANTAS, Rosycléa da Silva. O dizer sobre o fazer pedagógico: vozes e sentidos em um contexto de inclusão. Revista Investigações, vol. 27, n. 2, julho 2014. ISSN 2175-294X. Disponível em: https://periodicos.ufpe.br/revistas/INV/article/view/571/945. Acesso em 31 de março de 2021.

SANTOS, Rodolfo Rodrigues Pereira dos; IFA, Sérgio. O letramento crítico e o ensino de inglês: reflexões sobre a prática do professor em formação continuada. The ESPecialist, vol. 34, n. 1 (1-23) 2013. ISSN 2318-7115. Disponível em: https://revistas.pucsp.br/esp/article/view/19231. Acesso em: 05 de agosto de 2019.

MORRISON, Toni. A origem dos outros: seis ensaios sobre o racismo e a literatura. São Paulo: Companhia das Letras, p 66-89, 2019.

XAVIER, João Paulo. Letramento Crítico e o Ensino de Língua Estrangeira na Escola Pública: Brechas e Possibilidades", p. 26-39 . In: Anais do V Simpósio sobre o Livro Didático de Língua Materna e Língua Estrangeira \& do IV Simpósio sobre Materiais e Recursos Didáticos [=Blucher Design Proceedings, v.2, n.6]. São Paulo: Blucher, 2016. ISSN 2318-6968, DOI 10.5151/despro-v-silid-iv-simar-003. Disponível em 
PERcursos Linguísticos • Vitória (ES) •v. 11 •n. 27 • 2021 • ISSN: 2236-2592 • Dossiê: Pibid e RP na formação de professores em Letras •

https://www.proceedings.blucher.com.br/article-details/letramento-crtico-e-o-ensino-delngua-estrangeira-na-escola-pblica-brechas-e-possibilidades-22569. Acesso em: 05 de janeiro de 2021. 